\title{
Correlações entre pluviosidade e características produtivas em caprinos no semiárido paraibano
}

\section{Edgard Cavalcanti Pimenta Filho ${ }^{1}$, Sérgio Antonio de Normando Morais ${ }^{2}$, Roberto Germano Costa $^{3}$, Carla Cristina de Almeida ${ }^{4}$, Geovergue Rodrigues de Medeiros ${ }^{3}$}

\footnotetext{
${ }^{1}$ Departamento de Zootecnia - CCA/UFPB.

2 Escola Agrotécnica Federal de São Luís - MA.

3 Instituto Nacional do Semi-Árido - INSA.

${ }^{4}$ Agropecuária Manoel Dantas Ltda. - AMDA.
}

RESUMO - Avaliaram-se as correlações entre a pluviometria e as características produtivas em caprinos Pardo-Alpina $\times$ Gurgueia criados em regime semi-intensivo no Cariri Ocidental, microrregião semiárida do estado da Paraíba. Utilizaram-se informações de peso ao nascer, produção de leite, mortalidade dos cabritos até os 90 dias de idade e pluviosidade registrada na Fazenda Carnaúba. Os dados pluviométricos foram transformados para $\log _{\mathrm{X}}$. Houve baixa correlação entre o peso ao nascer, a produção de leite e mortalidade com as variáveis pluviométricas.

Palavras-chave: chuva, mortalidade, peso ao nascer, produção de leite

\section{Correlation among rainfall and productive traits of goats in the semi-arid region of Paraíba}

\begin{abstract}
The objective of this study was to evaluate the correlations between rainfall data and goat productive traits in Alpine $\times$ Gurgueia breeds goats, raised in a intensive regime in the Ocidental Cariri, a semi-arid microclime of Paraíba State, Brazil. Birth weight, milk production and mortality of kids to 90 days of age and rainfall data from the Carnauba Farm were used. The rainfall data were transformed in $\log _{\mathrm{x}}$. The birth weight, milk production and mortality correlated reasonably correlated with the rainfall variables. There was lower correlation among birth weight, milk production and mortality and the rainfall data.
\end{abstract}

Key Words: birth weight, milk production, mortality, rain

\section{Introdução}

É perceptível a importância da caprinocultura para o Nordeste brasileiro, o qual detém cerca de $92,6 \%$ do efetivo nacional (IBGE, 2006). Em regiões semiáridas, onde as condições edafo-climáticas dificultam a exploração agrícola, essa atividade já consolidou sua importância e viabilidade, despertando o interesse de criadores para a exploração de leite ou de carne e pele.

A caprinocultura tem sido uma atividade eficiente para o desenvolvimento sócio-econômico do semiárido, como atestam os dados do Programa do Leite da Paraíba (Governo do Estado da Paraíba, 2007). No entanto, com a rápida resposta dos criadores ao incentivo gerado pelo emergente mercado, é necessário melhorar a eficiência da produção, que continua dependendo de soluções tecnológicas.
Como a distribuição pluviométrica do semiárido é irregular, as respostas produtivas dependem da oferta estacional de forragem enquanto não se estabelece um modelo apropriado de produção de alimentos baseado em forrageiras nativas e adaptadas, em sistemas de cultivo desenvolvidos para as condições regionais, conjugadas com um sistema de conservação de forragens (Andrade et al., 2006).

Em outras regiões, o efeito de estação está associado às variações no comprimento do dia e na temperatura ambiente (Gootwine \& Rozov, 2006; Ylmaz et al., 2007). No entanto, nas condições da região semiárida brasileira, a principal fonte de variação estacional é a disponibilidade de umidade no solo, diretamente associada à pluviosidade e à produção da matéria forrageira (Andrade et al., 2006).

Nessa região, é na época seca que ocorrem menor desenvolvimento ponderal dos animais, estacionalidade 
reprodutiva, abortos, mortalidade e redução na produção de leite, uma consequência da insuficiente ingestão de nutrientes, principalmente quando não há adequada suplementação alimentar (Sánchez et al., 2003).

Além da produção de leite e do peso do cabrito ao nascer, a taxa de mortalidade de um rebanho é uma característica importante do ponto de vista produtivo do rebanho, pois reflete diretamente no lucro líquido anual do produtor e comprova, de maneira objetiva, o nível real de produtividade do rebanho.

Este trabalho foi realizado com o objetivo de avaliar a associação entre caracteres produtivos de caprinos com variáveis pluviométricas nas condições do semiárido paraibano.

\section{Material e Métodos}

O trabalho foi realizado com dados pluviométricos e produtivos de caprinos leiteiros mestiços Pardo-Alpina $\times$ Gurgueia de uma fazenda localizada na microrregião homogênea do Cariri Ocidental da Paraíba, mesorregião da Borborema, com as seguintes coordenadas geográficas; $7^{\circ} 12^{\prime} 23^{\prime \prime}$ de latitude Sul e $36^{\circ} 49^{\prime}$ '25" de longitude Oeste, e a uma altitude de $500 \mathrm{~m}$ do nível do mar.

Pela classificação de Köppen, o clima da região é do tipo BSWh' - clima seco do tipo estepe, com estação seca transladada do inverno para o outono, e temperatura média mensal muito alta durante todo o ano (Governo do Estado da Paraíba, 1987). O regime de chuvas da região é marcado por duas estações, uma chuvosa (3 a 4 meses) e outra estação mais longa e seca (8 e 9 meses). As chuvas são típicas das regiões áridas e semiáridas e se caracterizam, em geral, por serem do tipo monozônicas, torrenciais e concentradas em curto período de tempo (Tabela 1).

O rebanho era composto por animais mestiços resultantes do cruzamento seletivo de reprodutores PardoAlpinos com matrizes Gurgueia visando maior eficiência da produção de leite. O regime alimentar das cabras gestantes ou lactantes na época chuvosa era pastagem de capimbuffel (Cenchrus ciliares L), em sua maioria, e de algumas leguminosas nativas. Os animais recebiam ainda suplementação concentrada pela manhã e à tarde, na quantidade de $600 \mathrm{~g} /$ dia. Mistura mineral e melaço eram fornecidos à vontade aos animais.

Na época seca, as cabras recebiam suplementação volumosa diretamente no cocho, constituída de capimelefante (Pennisetum purpureum, Shum) verde picado, palma forrageira (Oputia ficus-indica), raspa de mandioca (Manihot utilissima, Pohl), feno de capim Buffel (Cenchrus ciliares $L$ ), cunhã ( Clitoria ternata $L$ ) verde picada ou em
Tabela 1 - Médias pluviométricas (mm) mensais registradas na região

\begin{tabular}{lccccc}
\hline \multirow{2}{*}{ Mês } & \multicolumn{5}{c}{ Ano } \\
\cline { 2 - 6 } & 1 & 2 & 3 & 4 & 5 \\
\hline Janeiro & 54,0 & 13,4 & 0,4 & 196,3 & 24,6 \\
Fevereiro & 23,2 & 44,0 & 83,5 & 87,5 & 16,8 \\
Março & 114,6 & 0,0 & 200,5 & 48,3 & 0,8 \\
Abril & 195,8 & 26,0 & 79,9 & 97,8 & 3,5 \\
Maio & 57,9 & 12,9 & 67,2 & 5,5 & 118,4 \\
Junho & 106,1 & 17,4 & 3,4 & 18,5 & 6,3 \\
Julho & 56,4 & 13,3 & 0,0 & 14,3 & 18,6 \\
Agosto & 15,5 & 22,3 & 14,8 & 2,1 & 0,0 \\
Setembro & 0,0 & 14,8 & 0,0 & 29,1 & 30,5 \\
Outubro & 11,7 & 0,5 & 0,0 & 0,0 & 0,0 \\
Novembro & 0,0 & 0,0 & 29,5 & 0,0 & 0,0 \\
Dezembro & 78,3 & 0,0 & 0,0 & 0,0 & 0,0 \\
\hline Total & 713,4 & 164,6 & 479,2 & 499,7 & 219,5 \\
\hline
\end{tabular}

forma de feno e leucena (Leucaena leucocephala), além de mistura mineral à vontade.

Os cabritos recém-nascidos mamavam o colostro e depois de sete dias eram separados das mães e mantidos em cabriteiro coletivo, sob aleitamento artificial com leite de vaca como sucedâneo, até aos 90 dias de idade, quando ocorria o desmame. Aproximadamente aos 120-150 dias, as cabritas passavam para o lote de matrizes e eram cobertas na ocasião do primeiro cio fértil. Após a primeira parição, eram incorporadas ao lote de cabras adultas, porém inicialmente eram alimentadas separadamente das cabras adultas.

Foram utilizados 851 registros de peso ao nascer, 557 lactações e de mortalidade dos cabritos até aos 90 dias de idade, referentes a cinco anos, oriundos do banco de dados pertencente à Fazenda Carnaúba. As informações das precipitações pluviométricas foram coletadas em pluviômetro existente na própria fazenda.

Os dados referentes aos animais foram submetidos a seleção prévia para maior consistência das análises, enquanto os pluviométricos foram transformados para $\log _{X}$. As correlações de Pearson entre as características produtivas e as variáveis pluviométricas foram estimadas com auxílio do programa computacional SAS (1996). Consideraram-se os graus de associação entre as variáveis peso ao nascer (PN), mortalidade (M), produção total de leite (PTL), precipitação pluviométrica do mês do parto (PMP), número de dias com chuva no mês do parto acima de 5mm (DCMP), precipitação pluviométrica do mês anterior ao parto (PMAP) e número de dias com chuva acima de 5 mm no mês anterior ao parto (DCMAP). 


\section{Resultados e Discussão}

As correlações entre os pesos dos cabritos ao nascer e a precipitação do mês anterior ao parto (PMAP) e número de dias com chuva acima de $5 \mathrm{~mm}$ (DCMAP) foram significativas $(\mathrm{P}<0,05)$ (Tabela 2). As correlações entre as variáveis foram de 0,49 e 0,41, respectivamente, e indicam grau médio de associação entre estas variáveis.

Esses resultados evidenciam a importância do planejamento das práticas reprodutivas no semiárido, de modo que o terço final da gestação das cabras transcorra no período chuvoso, quando há disponibilidade de forragens na pastagem. É nessa fase da gestação que as matrizes apresentam maior demanda de nutrientes, principalmente energia e proteína, para mantença, acúmulo de reservas corporais para a futura lactação e, ainda, assegurar o rápido crescimento fetal. Medeiros et al. (2004) constataram efeito de época do parto sobre a variação de peso durante a gestação de cabras de diferentes grupos genéticos no semiárido.

Lima et al. (1988), no Ceará, verificaram que cabritos SRD nascidos na estação chuvosa foram mais pesados que os nascidos na estação seca, com pesos de 2,07 e 1,75 kg, respectivamente.

É consenso na literatura que fatores genéticos e ambientais, como as oscilações na disponibilidade e qualidade das pastagens, em consequência das condições climáticas, e no manejo nutricional e sanitário aplicado aos animais em cada ano, exercem influência sobre o peso ao nascer e sobrevivência dos cabritos (Silva \& Araújo, 2000, Mellado et al., 2000; Marai et al., 2002).

As correlações entre a taxa de mortalidade e a precipitação pluviométrica do mês do parto e dias com chuva acima de $5 \mathrm{~mm}$ foram significativas $(\mathrm{P}<0,05)$ (Tabela 3 ).

A associação entre a taxa de mortalidade, precipitação pluviométrica e número de dias com chuva acima de $5 \mathrm{~mm}$ evidencia a sensibilidade dos cabritos ao aumento da umidade e conseqüente susceptibilidade a problemas de saúde, seja de ordem respiratória seja relativa a gastroenterite. Awemu et al. (1999) verificaram alta mortalidade de cabritos
Red Sokoto nascidos no período chuvoso, em sistema semi-intensivo, com valores que variaram de 46 a 58\%, em virtude da elevada incidência de doenças ocorridas nesse período. Hailu et al. (2006), no entanto, observaram maior mortalidade de cabritos Borana e Arsi-Bale na estação seca, apesar de afirmarem que esperavam comportamento contrário, exatamente pela associação entre umidade e ocorrência de doenças e parasitoses.

Neste estudo, a taxa de mortalidade apresentou variação de 9,1 a 19,2\% entre os anos avaliados, taxas consideradas altas para cabritos de até 4 meses de idade. Essas variações estão relacionadas, em parte, à quantidade e distribuição de chuvas, tendo em vista que as maiores taxas de mortalidade ocorreram nos anos de maiores índices pluviométricos, como nos anos 1, 3 e 4, obtendo-se correlação estimada de aproximadamente 0,39 (Tabela 3), indicando que outras variáveis também se correlacionam com a taxa de mortalidade, como no manejo dos cabritos, associado às instalações, um importante fator, pois, do nascimento até o desmame, os animais permaneciam no cabriteiro recebendo aleitamento artificial e volumoso. Nessa instalação, o piso era cimentado, com pequena inclinação e coberto por uma "cama" de capim-elefante triturado e seco. Por ocasião das chuvas, essa cama retinha muita umidade, acarretando problemas sanitários aos animais. Essa umidade também era aumentada pela maior frequência de micção dos cabritos.

As principais causas de mortalidade dos animais foram pneumonia e enterites infecciosas, decorrentes da predisposição dos cabritos nessa fase de vida e das condições de manejo e umidade no cabriteiro. A taxa de mortalidade média nesse estudo foi de $14,9 \%$, inferior às encontradas na literatura (Husain et al., 1995; Hailu et al., 2006).

A correlação entre produção de leite e dias foi significativa $(\mathrm{P}<0,05)$ apenas com chuva acima de $5 \mathrm{~mm}$, porém baixa, com valor de aproximadamente 0,33 (Tabela 4 ). Essa baixa correlação entre produção de leite e pluviosidade (DCMP) foi ocasionada pelo manejo alimentar adotado para as cabras lactantes sob suplementação energética e proteica durante todo o ano.

Tabela 2 - Correlação entre peso ao nascer e pluviosidade do mês anterior ao parto

\begin{tabular}{lccccc}
\hline Variável & Variável & N $^{\circ}$ meses & Correlação & T & Valor de probabilidade \\
\hline Peso & PMAP & 48 & 0,4932 & 3,8454 & $0,0002^{*}$ \\
Peso & DCMP & 48 & 0,4112 & 3,0597 & $0,0018^{*}$ \\
\hline
\end{tabular}

*Significativo pelo teste $\mathrm{T}(\mathrm{P}<0,05)$.

${ }^{1}$ Valor de probabilidade.

PMP = pluviosidade do mês do parto.

DCMP = dias com pluviosidade superior a $5 \mathrm{~mm}$. 
Tabela 3 - Correlação entre a taxa de mortalidade e a pluviosidade do mês do parto

\begin{tabular}{lccccc}
\hline Variável & Variável & N $^{0}$ meses & Correlação & T & Valor-P \\
\hline Mortalidade & P M P & 51 & 0,3983 & 3,0399 & $0,0019^{*}$ \\
Mortalidade & DCMP & 51 & 0,5530 & 3,5741 & $0,0006^{*}$ \\
\hline
\end{tabular}

*Significativo pelo teste $\mathrm{T}(\mathrm{P}<0,05)$.

${ }^{1}$ Valor de probabilidade.

PMP = pluviosidade do mês do parto.

DCMP = dias com pluviosidade superior a $5 \mathrm{~mm}$.

Tabela 4 - Correlação entre a produção de leite e a pluviosidade do mês do parto

\begin{tabular}{lccccc}
\hline Variável & Variável & N $^{\circ}$ meses & Correlação & T & Valor-P \\
\hline Produção de leite & P M P & 51 & 0,2502 & 1,8090 & $0,383^{*}$ \\
Produção de leite & DCMP & 51 & 0,3323 & 2,4738 & $0,0084^{*}$ \\
\hline
\end{tabular}

* Significativo pelo teste $\mathrm{T}(\mathrm{P}<0,05)$.

$\mathrm{PMP}=$ pluviosidade do mês do parto.

DCMP = dias com pluviosidade superior a $5 \mathrm{~mm}$.

Nesse estudo, a produção de leite e a duração da lactação (médias de 233,7 kg e de 189 dias, respectivamente) podem ser consideradas satisfatórias, uma vez que dois terços do período estudado ocorreram sob condições de severa seca (Figura 1).

As cabras que apresentaram os melhores desempenhos foram aquelas que pariram no ano de maior índice de pluviosidade (713,4 mm) e regular distribuição das chuvas ao longo do período chuvoso (Tabela 1). A média de produção de leite por lactação registrada foi de $281,58 \mathrm{~kg}$.

No segundo ano do estudo, foi registrada pluviosidade de 164,6 mm, 333,4\% inferior à do ano 1, mas com distribuição regular a partir do mês de janeiro até setembro. A produção média das cabras foi de 254,8 kg de leite, próxima à das

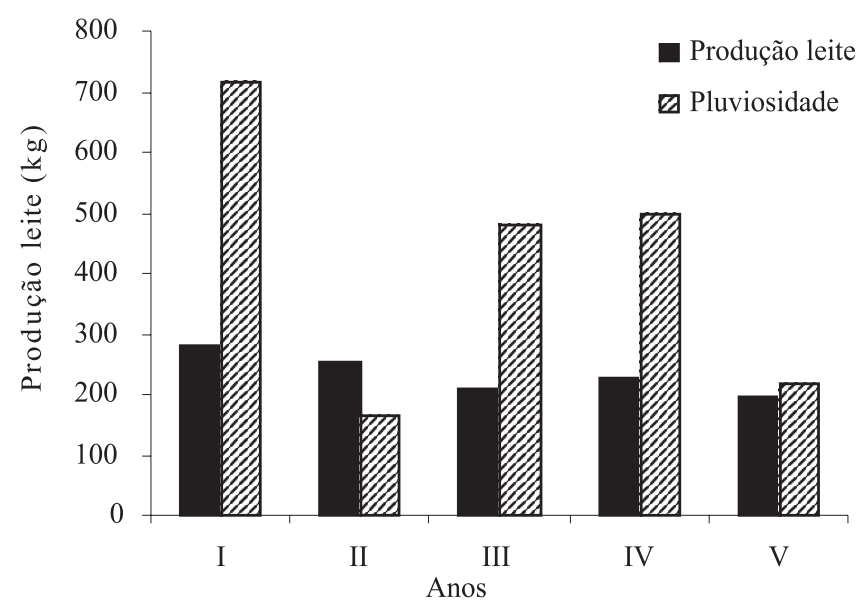

Figura 1 - Produção de leite e pluviosidade registradas durante o estudo. matrizes do ano anterior, o que está relacionado à regularidade das chuvas, que favoreceu o crescimento da pastagem e, também, ao reflexo positivo da produção excedente de forragens do ano 1 , permitindo sua conservação para utilização no período seco do ano 2 .

No ano 5, a pluviosidade foi de $219,5 \mathrm{~mm}$, porém com irregular distribuição das chuvas, como nos meses de março, abril, maio e junho, quando foi de 0,$8 ; 3,5 ; 118,4 \mathrm{e}$ $6,3 \mathrm{~mm}$, respectivamente. Nas condições de semiárido, o comportamento vegetal é fortemente influenciado pela pluviosidade, o que contribui para as variações no estado nutricional e o consequente desempenho produtivo das cabras. Nesse ano, a produção média foi de 194,96 kg de leite por cabra, o que corrobora relatos de Andrade et al. (2006) de que, em virtude da irregularidade das chuvas no semiárido, as respostas produtivas dependem da produção estacional de forragens.

\section{Conclusões}

O peso ao nascer e a mortalidade dos cabritos têm baixa associação com as variáveis pluviométricas, o que demanda maior atenção no manejo alimentar de cabras gestantes e das crias. A menor correlação das variáveis pluviométricas com a produção de leite confirma que manejo alimentar adequado pode contribuir para a redução da estacionalidade de produção.

\section{Agradecimentos}

À Agropecuária Manoel Dantas Ltda. (AMDA), pela cessão dos dados e irrestrito apoio para a realização do trabalho. 


\section{Literatura Citada}

ANDRADE, A.P.; SOUZA, E.S.; SILVA, D.S. et al. Produção animal no bioma caatinga: paradigmas dos pulsos-reserva. Revista Brasileira de Zootecnia, v.35, p.138-155, 2006 (supl. especial).

AWEMU, E.M.; NWAKALOR, L.N.; ABUBAKAR, B.Y. Technical Note: Enviromental influences on preweaning mortality and reproductive performance of Red Sokoto does. Small Ruminant Research, v.34, p.161-165, 1999.

GOOTWINE, E.; ROZOV, A. Seasonal effects on birth weight of lambs born to prolific ewes maintained under intensive management. Livestock Science. v.105, n.1-3, p.277-283, 2006.

GOVERNO DO ESTADO DA PARAÍBA [2007]. Governo quer fortalecer produção de leite de cabras. Disponível em: $<$ http://www.paraiba.pb.gov.br/indexindex.php?option= com_content\&task=view\&id=25483\&Itemid=2-20k $>$. Acesso em: 24/11/2007.

GOVERNO DO ESTADO DA PARAÍBA. Secretaria da Educação. UFPB. Atlas geográfico do estado da Paraíba. João Pessoa: Grafset, 1987.

HAILU, D.; MIESO, G.; NIGATU, A. et al. The effect of environment factors on preweaning survival rate of Borana and Arsi-Bale kids. Small Ruminant Research. v.66, n.1-3, p.291-294, 2006.

HUSAIN, S.S.; HORST, P.; ISLAM, A.B. Effect of different factors on preweaning survivability of Black Bengal Kids. Small Ruminant Research, v.18, n.1, p.1-5, 1995.

PESQUISA da Pecuária Municipal. Efetivo dos rebanhos de médio porte, segundo as Grandes Regiões e Unidades da Federação.
Rio de Janeiro: IBGE, 2006. Disponível em: <ftp://ftp.ibge. gov.br/Producao_Pecuaria/Producao_da_Pecuaria_ Municipal $>$. Acesso em: 25/3/2008.

LIMA, F.A.M.; SIMPLICIO, A.A.; FIGUEIREDO, E.A.P. et al. Traditional system of goat management. I-Reproductive performance de SRD does and kids mortality. Pesquisa Agropecuária Brasileira, v.23, n.9, p.1449-1458, 1988.

MARAI, I.F.M; ABOU-FANDOUD, E.I.; DAADER, A.H. et al. Technical note: Reproductive doe traits of the Nubian (Zaraibi) goats in Egypt. Small Ruminant Research, v.46, p.201-205, 2002.

MEDEIROS, G.R.; PIMENTA FILHO, E.C.; SOUZA, W.H. et al. Peso à cobrição e ganho de peso durante a gestação de cabras nativas, exóticas e mestiças no semi-árido. Revista Brasileira de Zootecnia, v.33, n.6, p.1711-1720, 2004.

MELLADO, M.; VERA, T.; HERRERA, C.M. et al. A note on the effect of air temperature during gestation on birth weight and neonatal mortality of kids. Journal of Agricultural Science, v.135, p.91-94, 2000.

SÁNCHEZ, C.; GARCÍA, M.; ÁlVAREZ, M. Efecto de la suplementación alimenticia sobre el comportamiento productivo de cabras al postparto en la microregión Río Tocuyo, estado Lara. Zootecnia Tropical, v.21, n.1, p.43-55, 2003.

SILVA, F.L.R.; ARAÚJO, A.M. Desempenho produtivo em caprinos mestiços no semi-árido do Nordeste do Brasil. Revista Brasileira de Zootecnia, v.29, n.4, p.1028-1035, 2000.

STATISTICAL ANALYSIS SYSTEM - SAS. SAS Technical report. Release 6.07. Cary: SAS Institute, 1996. 229p.

YLMAZ, O.; DENK, H.; BAYARAN, D. et al. Effects of lambing season, sex and birth type on growth performance of Norduz lambs. Small Ruminant Research, v.68, n.3, p.336-339, 2007. 